\title{
Unraveling misunderstandings about desertification: The paradoxical case of the Tabernas-Sorbas Basin in Southeast Spain
}

\author{
Jaime Martinez-Valderrama ${ }^{1}$, Emilio Guirado ${ }^{1}$, and Fernando Maestre ${ }^{1}$ \\ ${ }^{1}$ Universidad de Alicante
}

May 5, 2020

\begin{abstract}
From its origins, the concept of desertification has been controversial. The prevailing confusion between two desertification visions, one that considers it as the expansion of deserts and another that denotes its anthropogenic component, has been transferred to society. Here we illustrate misunderstandings about desertification using a very illustrative case from the TabernasSorbas Basin (Almeria, Spain), where striking badlands that are often used as an image of desertification coexist with an intensive olive agriculture that is deteriorating irreversibly the only oasis in continental Europe, Los Molinos spring. The olive tree is a traditional Mediterranean dryland crop and until the 1950s only about 200 ha were irrigated. However, the profitability of the crop has caused irrigation to expand to 4,400 ha in the last two decades. The process of intensification has been reinforced giving way to super-intensive irrigation, which involves going from 210 to 1,550 trees/ha and that in a few years already occupies more than 1,500 ha. The effects on the water balance of the aquifer feeding these crops have been severe and the flow of the Los Molinos spring has gone from more than $40 \mathrm{~L} / \mathrm{s}$ for the period 1970-2000 to the current $7.28 \mathrm{~L} / \mathrm{s}$. By unraveling the mechanisms of land degradation, we were able to detect its main drivers in the study area and, with them, to propose management actions to achieve a more sustainable use of resources and to combat desertification.
\end{abstract}

\section{Hosted file}

Manuscript_2_no_figures.doc available at https://authorea.com/users/302824/articles/432901unraveling-misunderstandings-about-desertification-the-paradoxical-case-of-the-tabernassorbas-basin-in-southeast-spain 

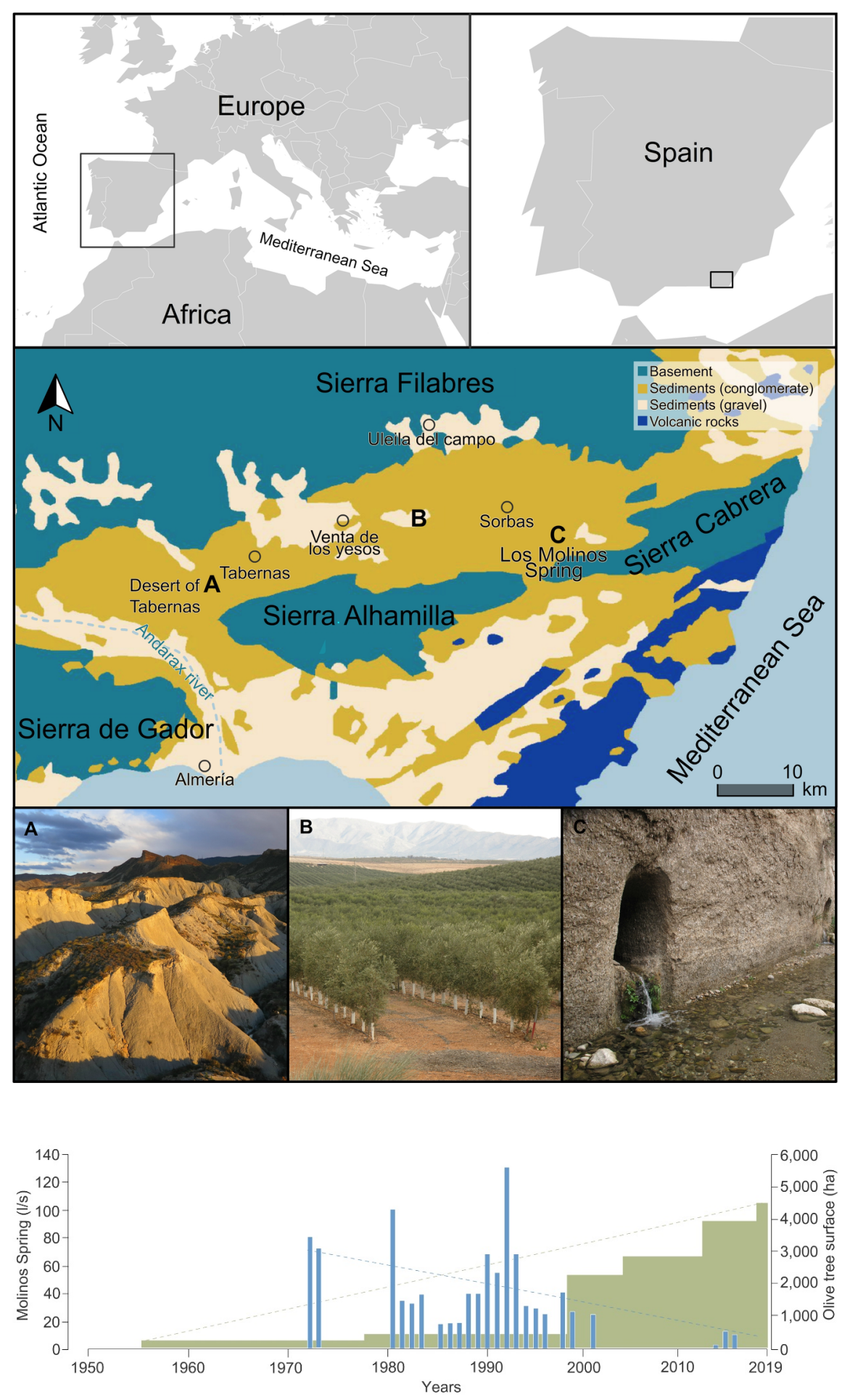


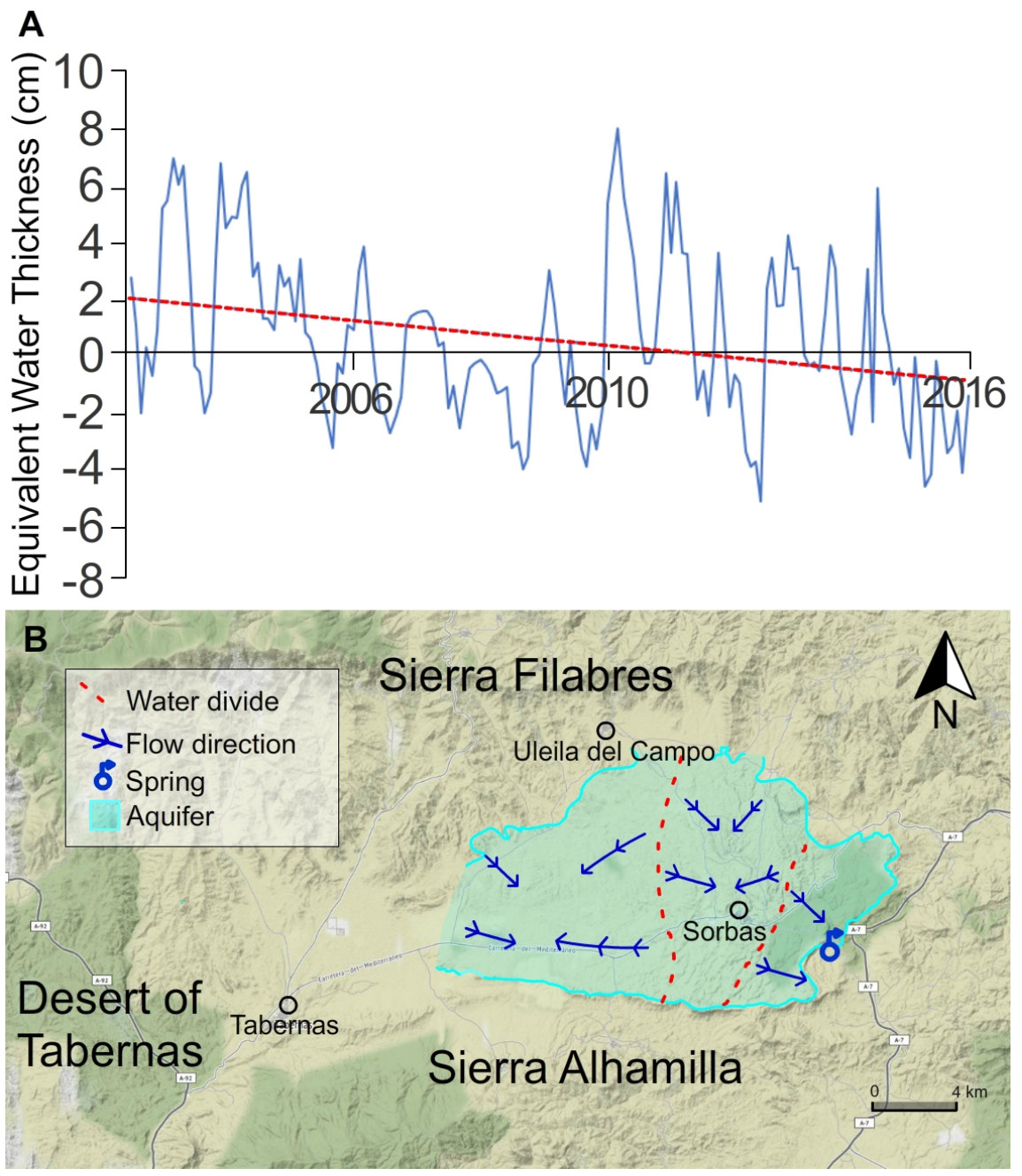

